\title{
Initial American Experience with Hip Resurfacing Following FDA Approval
}

\author{
Craig J. Della Valle MD, Ryan M. Nunley MD, \\ Stephen J. Raterman MD, Robert L. Barrack MD
}

Published online: 24 October 2008

(C) The Association of Bone and Joint Surgeons 2008

\begin{abstract}
In May 2006, the US Food and Drug Administration approved the first metal-on-metal total hip resurfacing. Surgeons wanting to implant this device were required to undergo formal industry-sponsored training before performing their first case and a technical specialist attended their initial 10 cases. Safety surveys were completed on the first 537 cases performed and included patient age, gender, diagnosis, and occurrence of any unexpected events perioperatively or postoperatively. Intraoperative data were available for all 537 cases (100\%), hospital discharge and six-week data were available for 524 cases $(97.6 \%)$, three-month data were available for 523 cases $(97.4 \%)$, six-month data were available for 509 cases (94.3\%) and one-year data were available for 449 cases (83.6\%); the mean followup was 10.4 months. We documented adverse events in 40 ( 32 major, 8 minor) of the 537 cases including nine nerve injuries and eight dislocations. There were 14 component revisions (7.4\%) within the first
\end{abstract}

One or more of the authors have received funding from Smith and Nephew (RMN, SJR, RLB), Zimmer (CJDV), and Stryker (CJDV).

Each author certifies that his or her institution has approved or waived the human protocol for this investigation and that all investigations were conducted in conformity with ethical principles of research.

\section{J. Della Valle $(\square)$}

Department of Orthopaedic Surgery, Rush University Medical Center, 1725 West Harrison, Suite 1063, Chicago, IL 60612, USA

e-mail: craigdv@yahoo.com

R. M. Nunley, R. L. Barrack

Department of Orthopaedic Surgery, Washington University

Medical Center, St Louis, MO, USA

\section{S. J. Raterman}

Department of Orthopaedic Surgery, University of South

Florida, Tampa, FL, USA year, including 10 for femoral neck fracture, two for dislocations, and two for acetabular component loosening. Complications were frequently seen among patients older than 55 years of age and in women, emphasizing the importance of appropriate patient selection for the procedure.

Level of Evidence: Level IV, therapeutic study. See the Guidelines for Authors for a complete description of levels of evidence.

\section{Introduction}

Modern metal-on-metal total hip resurfacing has been performed extensively outside of the United States for more than 10 years $[8,19]$. Experience within the United States has previously been limited to experienced hip surgeons performing the procedure as part of Food and Drug Administration (FDA) Investigational Device Exemption studies or on a so-called "off-label" basis [1, 18]. In May 2006, the Birmingham Hip Resurfacing (BHR; Smith and Nephew, Memphis, TN) was the first FDA-approved hip resurfacing device with the proviso that surgeons implanting the device would have to undergo mandatory training before their first case.

Hip resurfacing is generally viewed as being more technically challenging than standard THA, because retention of the femoral head makes visualization of the acetabulum more difficult [7, 16]. Furthermore, accurate femoral component placement can be tricky. Consequences of inaccurate femoral head preparation include an increased risk of femoral neck fracture $[3,5,21]$ and the sacrifice of additional acetabular bone stock if an overly large component size is selected to avoid a femoral neck notch [15]. 
We sought to identify: (1) the adverse events and complications encountered, (2) their outcomes, and (3) any patient demographic features associated with these adverse events.

\section{Materials and Methods}

The first 537 BHRs (the total number of patients is unknown given the data on the hips was deidentified) performed in the United States were performed by 89 surgeons between June and October 2006. Each surgeon was asked to complete an adverse event reporting form for each case at the completion of the operative procedure, at the time of discharge from the hospital, at six weeks, three months, six months and one year postoperatively. The adverse event reporting forms were then returned either to the implant manufacturer or to the first author (CDV) who collected, collated and analyzed the data. If data forms were initially not provided, the authors contacted the surgeon and asked them to send the forms, or recorded patients as lost to followup if this was the disposition reported by the operating surgeon.

Demographic data were provided by the surgeons for 471 of the 537 cases $(87.7 \%)$. The known cohort demographics included 334 men (70.9\%) and 137 women $(29.1 \%)$ with a mean age of 52 years (range, 16-82 years) at the time of surgery. Diagnosis data were provided for 460 hips and included osteoarthritis in $88.7 \%$ (414 hips), osteonecrosis in 5.9\% (27 hips), developmental dysplasia of the hip in 3\% (14 hips), and posttraumatic arthritis in $1.7 \%$ (eight hips); the diagnosis was listed as "other" in three hips $(0.7 \%)$ without further information provided.

Intraoperative data were available for all 537 cases (100\%), hospital discharge and six-week data were available for 524 cases $(97.6 \%)$, three-month data were available for 523 cases $(97.4 \%)$, six-month data were available for 509 cases $(94.3 \%)$ and one-year data were available for 449 cases $(83.6 \%)$. The unreported data points were either from patients who were lost to followup by the treating surgeon or for whom the treating surgeons did not provide further data. Mean followup was 10.4 months (range, immediate postoperative to 12 months).

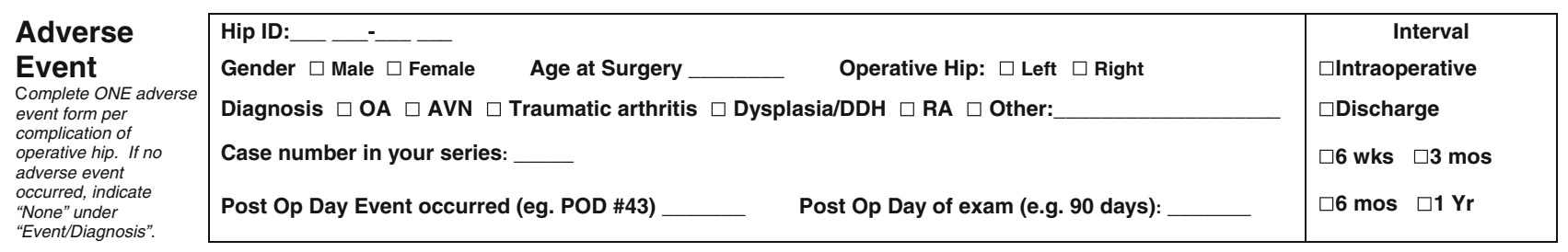

\begin{tabular}{|c|c|c|c|c|}
\hline Event/Diagnosis & Additional Comments? & & Treatment & $\begin{array}{l}\text { Outcome }{ }^{*} \\
\text { *Date required for death or } \\
\text { revision }\end{array}$ \\
\hline $\begin{array}{l}\square \text { NONE (if this box is checked, no other information is required) } \\
\text { If an event occurred, it was (interval): } \\
\square \text { Intraoperative } \quad \square \text { Postoperative } \\
\text { Specify the event (check all that apply): } \\
\square \text { Femoral neck notching } \\
\square \text { Femoral neck fracture } \\
\square \text { Femoral head collapse } \\
\square \text { Femoral head AVN (per x-ray) } \\
\square \text { Dislocation } \\
\square \text { Leg length discrepancy } \geq 0.5 \text { inches (1.27 cm) } \\
\square \text { Nerve injury due to surgery procedure } \\
\square \text { Nerve injury due to intraoperative positioning } \\
\square \text { Deep Infection } \\
\square \text { DVT } \\
\square \text { PE } \\
\square \text { Cup Loosening } \\
\square \text { Head Loosening } \\
\square \text { Other: }\end{array}$ & & $\square$ & $\begin{array}{l}\text { None } \\
\text { Medication/Orthotics } \\
\text { Procedure (not study hip } \\
\text { related)) } \\
\text { Procedure (study hip) } \\
\square \quad \text { Invasive or surgical } \\
\text { procedure } \\
\square \quad \text { Noninvasive procedure }\end{array}$ & $\begin{array}{ll}\square & \text { Resolved } \\
\square & \text { Ongoing/Unresolved } \\
\square & \text { Death } \\
& \text { *Post Op Day \#__ } \\
\square & \text { Removal or Revision of } \\
\text { component(s) } \\
\text { *Post Op Day \#__ } \\
\text { Components } \\
\text { removed/revised: } \\
\square \text { Femoral head } \\
\square \text { Acetabular cup }\end{array}$ \\
\hline
\end{tabular}

Hospital (Inpatient or Outpatient) Readmission Required? $\square$ No $\square$ Yes; Readmission Post Op Day number (e.g. POD\#43)

Surgeon Name:

Date: (MM/DD/YY)

Fig. 1 The adverse event reporting form is shown. 
All procedures were performed by surgeons who attended a mandatory classroom session. This session focused on the technical aspects of the procedure, including familiarization with the instruments, practice using saw bones, and preoperative planning. Appropriate patient selection was also discussed, including the recommendation that optimal results are seen among men less than 65 years old, females less than 55 years old and patients with degenerative joint disease or osteonecrosis with less than $30 \%$ involvement of the femoral head. All surgeons subsequently attended live surgery (a minimum of two cases performed by a surgeon outside of the United States who was experienced in performing the procedure). An individual surgeon's first 10 cases were attended by a technical specialist from the implant vendor with extensive prior experience with the procedure to further assist with any technical issues encountered by the surgeon or the operating room staff. All surgeons agreed to participate in adverse event reporting (using deidentified patient data) for the purposes of this study. Surgeons performed a mean of six cases during the study period (range, 1-45 cases).

The adverse event reporting form (Fig. 1) included patient demographics, preoperative diagnosis, the timing of any adverse event (intraoperative and postoperative), a description of the event and its treatment as well as associated outcomes. None of the data collected included personal identifiers.

\section{Results}

Thirty-two major adverse events were recorded (Table 1), including 10 femoral neck fractures $(2.0 \%$ of the 509 patients with 6-month followup) (Table 2). The mean age of the patients with a femoral neck fracture was 59 years (range, $42-82$ years). Nine of the 10 femoral neck fractures
Table 1. Major complications

\begin{tabular}{lc}
\hline Complication & Number \\
\hline Femoral neck fracture & 10 \\
Dislocation & 8 \\
Nerve injury & 9 \\
Subtrochanteric femur fracture & 2 \\
Acetabular component loosening & 2 \\
Deep infection & 1 \\
Total & 32 \\
\hline
\end{tabular}

occurred in patients who were either female or older than 55 years at the time of surgery (Table 2). Eight of the 10 femoral neck fractures occurred within the surgeons' first 10 cases with two being the surgeon's first case. The femoral neck fractures occurred at a mean of 62 days postoperatively (range, 16-176 days); eight of the 10 occurred within 60 days of surgery.

Eight patients had a dislocation of the operative hip (1.7\% of the 465 patients with 1-year followup) (Table 3) $[8,9,19]$. Four of the eight were dislocations noted on recovery room films and were managed with a single closed reduction without further recurrence. Two of the dislocations occurred in the early postoperative period (at 4 and 8 days postoperatively); in one, the hip resurfacing was revised to a THA with revision of both components. In the second, the acetabular component was believed too vertical and was revised without further episodes of instability; the patient, however, had persistent pain and underwent a second revision to a stemmed femoral component. The remaining two dislocations occurred later (at 51 and 326 days postoperatively) in association with a traumatic episode. The patient who dislocated at 51 days sustained a second dislocation at 16 months postoperatively while performing yoga and was treated with a second closed

Table 2. Femoral neck fractures

\begin{tabular}{|c|c|c|c|c|c|}
\hline Gender & Age (years) & $\begin{array}{l}\text { Case number } \\
\text { for surgeon }\end{array}$ & Postoperative day & Diagnosis & Treatment \\
\hline Female & 42 & 1 & 16 & Osteoarthritis & Femoral revision \\
\hline Male & 57 & 1 & 27 & Osteoarthritis & Femoral revision \\
\hline Female & 59 & 2 & 29 & Osteoarthritis & Revision both components \\
\hline Female & 59 & 3 & 77 & Osteoarthritis & Revision both components \\
\hline Male & 63 & 3 & 111 & Osteoarthritis & Femoral revision \\
\hline Female & 56 & 4 & 22 & Osteoarthritis & Revision both components \\
\hline Male & 63 & 6 & 186 & Osteoarthritis & Femoral revision \\
\hline Male & 49 & 6 & 57 & Osteonecrosis & $\begin{array}{l}\text { Internal fixation (failed); } \\
\text { eventual femoral revision }\end{array}$ \\
\hline Male & 82 & 11 & 58 & Osteoarthritis & Femoral revision \\
\hline Male & 62 & 38 & 38 & Osteoarthritis & Femoral revision \\
\hline
\end{tabular}


Table 3. Dislocations

\begin{tabular}{lllcll}
\hline Gender & Age (years) & Case number for surgeon & Postoperative day & Diagnosis & Treatment \\
\hline Male & 61 & 1 & 0 & Osteoarthritis & Closed reduction \\
Male & 48 & 2 & 0 & Osteoarthritis & Closed reduction \\
Female & 57 & 2 & 8 & Osteoarthritis & Revision both components \\
Female & 54 & 7 & 4 & Osteonecrosis & Acetabular component revision \\
Male & 33 & 11 & 0 & Osteoarthritis & Closed reduction \\
Female & 65 & 19 & 326 & Osteoarthritis & Closed reduction \\
Female & 41 & 21 & 0 & Hip dysplasia & Closed reduction \\
Female & 62 & 36 & 51 & Osteoarthritis & Closed reduction x 2 \\
\hline
\end{tabular}

Table 4. Nerve injuries

\begin{tabular}{llllll}
\hline Gender & Age (years) & Case number for surgeon & Involvement & Diagnosis & Outcome \\
\hline Male & 60 & 1 & Femoral & Posttraumatic & Recovery \\
Male & 58 & 2 & Peroneal & Osteoarthritis & Osteoarthritis \\
Female & 56 & 3 & Sciatic & Recovery \\
Male & 35 & 3 & Femoral & Osteoarthritis & Recovery \\
Male & 46 & 4 & Peroneal & Osteoarthritis & Recovery \\
Female & 46 & 7 & Peroneal & Osteoarthritis & Recovery \\
Male & 60 & 13 & Sciatic & Osteoarthritis & Unresolved \\
Male & 59 & 26 & Peroneal & Osteoarthritis & Recovery \\
Female & 54 & 26 & Sciatic & Osteoarthritis & Recovery \\
\hline
\end{tabular}

reduction, whereas the second patient has not had any further episodes of instability. The mean age of these eight patients with dislocations was 53 years (range, 33-65 years). Four of these eight cases were among the surgeons' first 10 cases.

Nine patients sustained a nerve injury (1.7\% of the 524 patients with hospital discharge data) (Table 4). Four of the nerve injuries involved the peroneal division of the sciatic nerve, three were complete sciatic nerve palsies, and two involved the femoral nerve. The mean age of these patients was 53 years (range, 35-60 years). Six of these nine nerve injuries occurred among the surgeons' first 10 cases. At the time of most recent followup, seven of the nine patients were reported to have recovered from the nerve injury.

There was one postoperative infection in a 47-year-old man treated with operative débridement on postoperative Day 7. The patient underwent a second débridement several days after the first and at 1 year has retained the components without overt evidence of persistent infection. There were two subtrochanteric femur fractures. The first occurred in a 62-year-old woman who fell on postoperative Day 7 and fractured through the site where the guide pin had exited the lateral femoral cortex; the fracture was successfully treated with open reduction and internal fixation (with retention of the components). The second subtrochanteric fracture occurred 14 months postoperatively in a 56-year-old woman who fell on the operative hip; the fracture was treated with open reduction and internal fixation (with component retention) and healed. Two patients underwent isolated acetabular revision (with retention of the resurfacing femoral component and insertion of a new BHR cup) for aseptic loosening, one at 6 months and the second at 17 months postoperatively. No pulmonary emboli or deep vein thrombi were reported.

There were eight recorded minor adverse events (Table 5). There were three femoral neck notches none of which resulted in a femoral neck fracture; two occurred within the first 10 patients in the surgeons' series and the third occurred at Case Number 25. Two were treated with protected weightbearing for 6 weeks and have been seen at 1 year without any associated sequelae. The third femoral neck notch was converted intraoperatively to a THA. There were four cases in which the surgeon reported the acetabular component was not fully seated on the postoperative radiographs. All four cases were in males and these patients

Table 5. Minor adverse events

\begin{tabular}{ll}
\hline Complication & Number \\
\hline Femoral neck notching without fracture & 3 \\
Hematoma & 1 \\
Incomplete cup seating & 4 \\
Total & 8 \\
\hline
\end{tabular}


had a mean age of 46 years (range, 40-49 years). Three of these cases occurred in the surgeons' first 10 cases and the fourth was the surgeon's 37th case. None of these cases have resulted in the need for reoperation. One patient developed a postoperative hematoma for which operative débridement was performed on postoperative Day 4.

\section{Discussion}

Hip resurfacing can only be considered a viable alternative to THA if it can be reasonably taught to surgeons and subsequently performed with an acceptable risk of complications. Legitimate concern has been raised that given the more technically demanding nature of hip resurfacing, the rate of complications may be unacceptably high. The goal of this report was to describe the early experience with metalon-metal hip resurfacing, following FDA approval of the first device in the United States, with a focus on the risk of early post-operative complications, associated treatment and any demographic associations with these complications.

One of the limitations of this study is the inclusion of a large number of surgeons with varying levels of experience with hip surgery. However, the use of such a mixed population of surgeons may provide a better estimate of what the "average" orthopaedic surgeon can expect [4]. Further, no radiographs were reviewed as part of this study. However, the early complications that we sought to identify should not have been hampered by the lack of a radiographic review. Furthermore, because complete 1 year data were not available for all 540 cases, the results reported here represent the minimum and the actual rate may have been higher if followup on all patients had been received. What remains unknown is if the risk of hip resurfacing is associated with a higher risk of complications than standard THA. Because this study was observational and not randomized, this critical question remains unanswered.
The most commonly reported complication of hip resurfacing is femoral neck fracture. Femoral neck fracture has been associated with both technical error and patientrelated factors, including advanced age, female gender, and decreased bone density (Table 6) [3, 5, 16, 18, 21, 22]. A femoral neck fracture was seen in $2 \%$ of cases in this series with 6 months followup, which is similar to the $1.46 \%$ rate reported in the largest known series to date [21] and far lower than the rate of $7.2 \%$ reported in one series focusing on the learning curve associated with the procedure [18]. Consistent with prior literature, patient-related factors (notably age and female gender) seem to have been important in the occurrence of this complication with three of the cases being in women who were older than 55 years of age, five being in men older than 55 years of age, and nine of the 10 occurring in patients who were either female or older than 55 years of age. Both surgeons and patients should be aware of the importance of patient selection when deciding on hip resurfacing as opposed to conventional THA. Although the seriousness of this complication cannot be overemphasized, the popularity of cementless femoral reconstruction in the United States has been associated with an increased risk of periprosthetic femoral fracture in association with conventional THA $[6,17]$.

Nine nerve injuries were reported in this series, for a rate of $1.7 \%$, with six of the nine occurring among the surgeons' first 10 cases. In one of the largest published series to date, the risk of nerve palsy was 16 of $1000(1.6 \%)$ [14], which is similar to the risk noted in this report. In a report of 230 BHRs followed for a mean of 5 years, five nerve palsies were noted (2.2\%; two sciatic, two femoral, one common peroneal) with all recovering at the most recent evaluation [12]. Schmalzried et al. [20] estimated the risk of nerve palsy at approximately $1 \%$ after standard THA, although other large series have estimated the risk is lower, at approximately $0.2 \%$ [10]. Retention of the femoral head in resurfacing arthroplasty complicates exposure, and the

Table 6. Reported femoral neck fracture rates following metal-on-metal hip resurfacing

\begin{tabular}{lrrll}
\hline Author & Year & \# Hips & $\begin{array}{l}\text { Fracture } \\
\text { rate }\end{array}$ & Notes \\
\hline Amstutz et al. [1] & 2007 & 350 & $0.3 \%$ & All patients < 50 years old \\
Amstutz et al. [2] & 2004 & 400 & $0.8 \%$ & Mean age 48 years; 73\% male \\
Back et al. [5] & 2005 & 230 & $0.4 \%$ & Single femoral neck fracture treated non-operatively; mean age 52 years, 65\% male \\
Daniel et al. [8] & 2004 & 446 & $0 \%$ & All patients < 55 years old and osteoarthritis \\
De Smet [9] & 2005 & 252 & $0.4 \%$ & Mean age 49.7 years old; 70\% male \\
Le Duff et al. [14] & 2007 & 770 & $0.9 \%$ & Rate of femoral neck fracture similar between obese and non-obese \\
Marker et al. [16] & 2007 & 550 & $2.5 \%$ & 12 of 14 fractures within first 69 of series \\
Mont et al. [18] & 2007 & 1016 & $2.7 \%$ & Reduction in fracture rate from 7.2\% to 0.8\% with changes in indications and technique \\
Shimmin and Back [21] & 2005 & 3497 & $1.5 \%$ & Rate 1.91\% for women and 0.98\% for men; technical error identified in 85\% of cases \\
Della Valle et al. & 2008 & 509 & $2.0 \%$ & 9 of 10 fractures in patients who were either female of $>55$ years old \\
\hline
\end{tabular}


higher risk of nerve injury associated with hip resurfacing may be attributable to difficulties in gaining adequate exposure of the acetabulum. In addition, retraction of the femoral head anteriorly may directly compress the femoral nerve during exposure. Given the higher risk reported in this study and other reports, it may be prudent to fully release the hip capsule and gluteus maximus tendon insertion to ease exposure and limit forceful retraction.

A purported benefit of resurfacing arthroplasty of the hip is a decreased risk of dislocation; however, eight dislocations were noted in this study (1.8\%). Although this number appears high, it is important to note four of the dislocations were seen on the recovery room radiographs and have not resulted in recurrent instability. Given the complete capsulotomy recommended for hip resurfacing, it is possible a dislocation might occur when neuraxial anesthesia results in lower extremity paralysis. Several other series have reported no dislocations after hip resurfacing $[2,5,8]$, although in one series of 1000 patients, the risk of dislocation was $0.9 \%$ [14], which is the same rate we found if the recovery room dislocations are excluded. Two of the dislocations in the present report were managed with early revision surgery, one for a vertically placed acetabular component indicating the importance of appropriate acetabular component placement, even when a largesized femoral head is used. In one large series of 19,680 conventional THAs performed at a tertiary care center, the incidence of dislocation was $1.8 \%$ at 1 year and $7 \%$ at 25 years [24] indicating the risk of dislocation may be lower with hip resurfacing, even when performed by surgeons with minimal prior experience in the technique. Several studies $[11,13,23]$ demonstrate the risk of dislocation after conventional THA is related to surgical experience and thus with increased familiarity with the technique, the risk of dislocation with hip resurfacing would be expected to decrease as well.

Results from the Australian Hip Registry suggest that although the overall rate of early revision is higher as a whole, in target populations (males and patients younger than 55 years of age), the early revision rate is the same as conventional THA [7]. There were 14 early revisions in this study (3\% of the hips with followup of at least 1 year), which is similar to what has been reported in the Australian Registry [7] for hip resurfacing (2.8\%), albeit at a shorter time to followup.

Acknowledgments We thank the operating surgeons (and their staff) who contributed their clinical material and time to this study.

\section{References}

1. Amstutz HC, Ball ST, Le Duff MJ, Dorey FJ. Resurfacing THA for patients younger than 50 years: results of 2- to 9-year followup. Clin Orthop Relat Res. 2007;460:159-164.
2. Amstutz HC, Beaule PE, Dorey FJ, Le Duff MJ, Campbell PA, Gruen TA. Metal-on-metal hybrid surface arthroplasty: two to six-year follow-up study. J Bone Joint Surg Am. 2004;86:28-39.

3. Anglin C, Masri BA, Tonetti J, Hodgson AJ, Greidanus NV. Hip resurfacing femoral neck fracture influenced by valgus placement. Clin Orthop Relat Res. 2007;465:71-79.

4. Archibeck MJ, White RE Jr. Learning curve for the two-incision total hip replacement. Clin Orthop Relat Res. 2004;429:232-238.

5. Back DL, Dalziel R, Young D, Shimmin A. Early results of primary Birmingham hip resurfacings. An independent prospective study of the first 230 hips. J Bone Joint Surg Br. 2005; 87:324-329.

6. Berend ME, Smith A, Meding JB, Ritter MA, Lynch T, Davis K. Long-term outcome and risk factors of proximal femoral fracture in uncemented and cemented total hip arthroplasty in 2551 hips. J Arthroplasty. 2006;21(Suppl 2):53-59.

7. Buergi ML, Walter WL. Hip resurfacing arthroplasty: the Australian experience. J Arthroplasty. 2007;22(Suppl 3):61-65.

8. Daniel J, Pynsent PB, McMinn DJ. Metal-on-metal resurfacing of the hip in patients under the age of 55 years with osteoarthritis. J Bone Joint Surg Br. 2004;86:177-184.

9. De Smet KA. Belgium experience with metal-on-metal surface arthroplasty. Orthop Clin North Am. 2005;36:203-213, ix.

10. Farrell CM, Springer BD, Haidukewych GJ, Morrey BF. Motor nerve palsy following primary total hip arthroplasty. J Bone Joint Surg Am. 2005;87:2619-2625.

11. Hedlundh U, Ahnfelt L, Hybbinette CH, Weckstrom J, Fredin H. Surgical experience related to dislocations after total hip arthroplasty. J Bone Joint Surg Br. 1996;78:206-209.

12. Hing CB, Back DL, Bailey M, Young DA, Dalziel RE, Shimmin AJ. The results of primary Birmingham hip resurfacings at a mean of five years: an independent prospective review of the first 230 hips. J Bone Joint Surg Br. 2007;89:1431-1438.

13. Katz JN, Losina E, Barrett J, Phillips CB, Mahomed NN, Lew RA, Guadagnoli E, Harris WH, Poss R, Baron JA. Association between hospital and surgeon procedure volume and outcomes of total hip replacement in the United States Medicare population. J Bone Joint Surg Am. 2001;83:1622-1629.

14. Le Duff MJ, Amstutz HC, Dorey FJ. Metal-on-metal hip resurfacing for obese patients. J Bone Joint Surg Am. 2007;89:27052711.

15. Loughead JM, Starks I, Chesney D, Matthews JN, McCaskie AW, Holland JP. Removal of acetabular bone in resurfacing arthroplasty of the hip: a comparison with hybrid total hip arthroplasty. J Bone Joint Surg Br. 2006;88:31-34.

16. Marker DR, Seyler TM, Jinnah RH, Delanois RE, Ulrich SD, Mont MA. Femoral neck fractures after metal-on-metal total hip resurfacing: a prospective cohort study. $J$ Arthroplasty. 2007;22(Suppl 3):66-71.

17. Mitchell PA, Greidanus NV, Masri BA, Garbuz DS, Duncan CP. The prevention of periprosthetic fractures of the femur during and after total hip arthroplasty. Instr Course Lect. 2003;52:301-308.

18. Mont MA, Seyler TM, Ulrich SD, Beaule PE, Boyd HS, Grecula MJ, Goldberg VM, Kennedy WR, Marker DR, Schmalzried TP, Sparling EA, Vail TP, Amstutz HC. Effect of changing indications and techniques on total hip resurfacing. Clin Orthop Relat Res. 2007;465:63-70.

19. Revell MP, McBryde CW, Bhatnagar S, Pynsent PB, Treacy RB. Metal-on-metal hip resurfacing in osteonecrosis of the femoral head. J Bone Joint Surg Am. 2006;88(Suppl 3):98-103.

20. Schmalzried TP, Noordin S, Amstutz HC. Update on nerve palsy associated with total hip replacement. Clin Orthop Relat Res. 1997;344:188-206.

21. Shimmin AJ, Back D. Femoral neck fractures following Birmingham hip resurfacing: a national review of 50 cases. J Bone Joint Surg Br. 2005;87:463-464. 
22. Shimmin AJ, Bare J, Back DL. Complications associated with hip resurfacing arthroplasty. Orthop Clin North Am. 2005;36:187-193, ix.

23. Solomon DH, Losina E, Baron JA, Fossel AH, Guadagnoli E, Lingard EA, Miner A, Phillips CB, Katz JN. Contribution of hospital characteristics to the volume-outcome relationship: dislocation and infection following total hip replacement surgery. Arthritis Rheum. 2002;46:2436-2444.

24. von Knoch M, Berry DJ, Harmsen WS, Morrey BF. Late dislocation after total hip arthroplasty. J Bone Joint Surg Am. 2002; 84:1949-1953. 